\title{
Game-Enhanced Second Language Vocabulary Acquisition Strategies: A Systematic Review
}

\author{
Anastassiya Yudintseva \\ Department of Curriculum, Teaching and Learning, University of Manitoba, Winnipeg, Canada \\ Email: y anastassiya@hotmail.com \\ Received 21 September 2015; accepted 19 October 2015; published 23 October 2015 \\ Copyright (C) 2015 by author and Scientific Research Publishing Inc. \\ This work is licensed under the Creative Commons Attribution International License (CC BY). \\ http://creativecommons.org/licenses/by/4.0/

c) (7) Open Access

\begin{abstract}
This paper is a synthesis of $\mathbf{1 7}$ qualitative, quantitative, and mixed-method studies published over the last decade. The synthesis suggests that game-enhanced learning provides a set of effective strategies such as language repetitions, contextual clues, interaction with native speakers and peers, and imagery to practice and use second language vocabulary in the authentic context. Some of the strategies such as word lists, dictionaries, and vocabulary exercises are more beneficial when combined with native speakers or peers' interactions. Due to high interactivity of games, note taking and media strategies provide less support for vocabulary learning. The lack of high quality studies and empirical data makes it difficult to draw conclusions about which video games strategies provide the most benefit. The synthesis of research identifies that generally game-enhanced practices are helpful for second language vocabulary enhancement.
\end{abstract}

\section{Keywords}

Video Games, Vocabulary Acquisition, English as a Second Language

\section{Introduction}

Vocabulary is one of the most important components of successful and meaningful communication both in a mother tongue and in a target language. Hunt and Beglar [1] assert: "The heart of language comprehension and use is the lexicon”. On average, the educated native English speaker by the age of 20 knows approximately 20,000 word families [2]. It implies that throughout secondary education students learn around 12,000 word families; however, teachers explicitly introduce only $40 \%$ of them [3]. Most vocabulary both native speakers and second language learners acquire incidentally through "multiple exposures to a word in different contexts" [4] 
such as reading, listening, and interactions.

Vocabulary acquisition is evident if learners know the word's spoken and written forms, grammatical patterns and collocations, function, and meaning [5]. Vocabulary learning is a life-long process; therefore, mastery of these word knowledge types is gained gradually and randomly and at different rates [6]. To make this process more efficient, learners consciously use different learning strategies. Learning strategies refer to the techniques that are used for the enhancement of second language knowledge through self-directed learning activity. Moreover, language proficiency is closely linked to the effective application of these techniques [7].

A number of researchers proposed rationales of learning strategies for second language vocabulary acquisition [5] [8]. Schmitt [9] developed a comprehensive taxonomy based on Oxford's system [8], including social, memory, cognitive and metacognitive categories and Cook and Mayer's [10] and Nation's [5] distinction of discovery and consolidation strategies (Table 1).

Schmitt [9] asserts that second language learners acquire vocabulary initially through discovery of word's meaning (discovery strategies) and then by remembering the word (consolidation strategies) when its meaning has been already discovered. The meaning can be reached either independently (determination strategies) by guessing form contextual clues or socially (social strategies) by asking teachers or peers for help. Moreover, Schmitt [9] underlines the importance of interactions with native speakers (social strategies), contextual usage of words and imagery (memory strategies), verbal or written repetitions and taking notes (cognitive strategies), and media (metacognitive strategies) for better vocabulary remembering and retention. Thus, social strategies refer to the cooperation with others, memory strategies link new words with previously learned words, metacognitive control the learning process, and cognitive strategies are used for language manipulation and transformation [11].

In this view, gaming theorists argue that video games are "problem-solving spaces that create deep learning" [12] by means of co-design, problem-based, and situated meaning principles [13]. One of the beneficial aspects of video games for learning is the facilitation of inductive discovery, which requires learners to "formulate general rules, patterns, and strategies" in order to proceed with the game [14]; so that learners become co-designers of a game through trial-and-error [13]. According to Gee [13], video games create authentic and safe environment where learners enhance knowledge and skills by solving "well-ordered problems". These problems are built on the principle "from easy to difficult" [15] in such a way that the mastery of easy concepts leads to the understanding of more complex notions later. Finally, video games create deep understanding of lexicon by connecting game actions, goals, and images to learner's personal experience [13]. In addition, video games such as MMORPGs and real time strategy offer opportunities to practice second language skills through social interactions with native speakers in gaming communities [16], as well as with non-player characters in simulation and adventure games.

\section{Purpose of Research}

In the current state of Computer Assisted Language Learning domain, game-enhanced and game-based studies are recognized. Game-enhanced practices seek to understand the usage of commercial-off-the-shelf games for incidental language learning, while game-based practices explore the effects of serious games or synthetic immersive environments on language acquisition [17]. Commercial-off-the-shelf games, for instance, The Sims, World of Warcraft, L.A.Noire, and FIFA refer to video games that were developed for mass production with the

Table 1. Summary of vocabulary acquisition strategies and related activities for second language learners.

\begin{tabular}{lcl}
\hline DISCOVERY & Determination Strategies & Guessing meaning from contextual clues; using dictionary and word lists \\
STRATEGIES & Social Strategies & Scaffolding instructions from teachers, peers or collaboration activities \\
& Social Strategies & Interaction with native speakers \\
$\begin{array}{l}\text { CONSOLIDATION } \\
\text { STRATEGIES }\end{array}$ & Memory Strategies & $\begin{array}{l}\text { Imagining word's meaning; connecting with personal experience; using } \\
\text { new words in sentences, connect the word to its synonyms and antonyms } \\
\end{array}$ \\
& Cognitive Strategies & Verbal and written repetition, taking notes \\
& Metacognitive Strategies & Using media \\
\hline
\end{tabular}

Source: Adapted from [9]. 
sole purpose of entertainment, while serious games such as Tactical Iraqi, Food Force, Second Life, or Quizlet are created to support specific language objectives [18]. Although video games have been used for educational purposes for over 30 years [19], there is still no commonly accepted definition [20]. Thus, for the purpose of the current research synthesis, video game is a goal-directed [19] [21] challenging interaction [22] governed by a set of rules and feedback [13] [22]. This paper will focus on those video games that appear to enhance second language learners' vocabulary incidentally. Since technologies are constantly changing, the purpose of the present paper is to synthesize the recent findings of qualitative, quantitative, and mixed-method studies to determine the effectiveness of learning strategies on English as a second language vocabulary acquisition through game-ennced practices.

\section{Method}

Studies included in the analysis were derived from Google Scholar, ERIC, Scopus, IEEE Xplore, and Science Direct. The search was focused on articles published in peer-reviewed journals, PhD dissertations, and conference proceedings in the field of ESL, CALL, and gaming. To identify the literature, the search terms used were "video games" AND "vocabulary acquisition" AND "English as a second language". To be included in the analysis, publications had to 1) specify information on games (e.g., title, type, genre, features); 2) provide information on vocabulary strategies used for language acquisition through gaming; 3) contain evidence of video games effects on vocabulary acquisition; 4) recruit English as a second language participants; and 5) be published over the last decade (2005-2015). Studies that emphasized other second language skills acquisition, for example, listening, reading, or communication through video games and studies that applied serious games for intervention were excluded from the current systematic literature review.

Seventeen articles that met inclusion criteria were coded according to the strategies used for second language vocabulary acquisition: determination strategies, social strategies, memory strategies, cognitive strategies, and metacognitive strategies. Further, vocabulary strategies were coded based on related strategies used for vocabulary learning through video games. Determination strategies were categorized as contextual clues and dictionaries, word lists, and vocabulary exercises. Social strategies were classified as interactions with native speakers and interactions with peers. Memory strategies were coded as imagery. Cognitive strategies were categorized as note taking and verbal and written repetitions and metacognitive strategies as media.

\section{Results}

\subsection{Papers Identified by Search Terms}

Figure 1 reflects the number of papers identified in each database using the search terms. The initial search yielded 18,050 papers, however, only 17 publications met the inclusion criteria. The bulk of research was found in Google Scholar (70\%), followed by Science Direct (12\%), ERIC (6\%), Scopus (6\%), and IEEE Xplore (6\%).

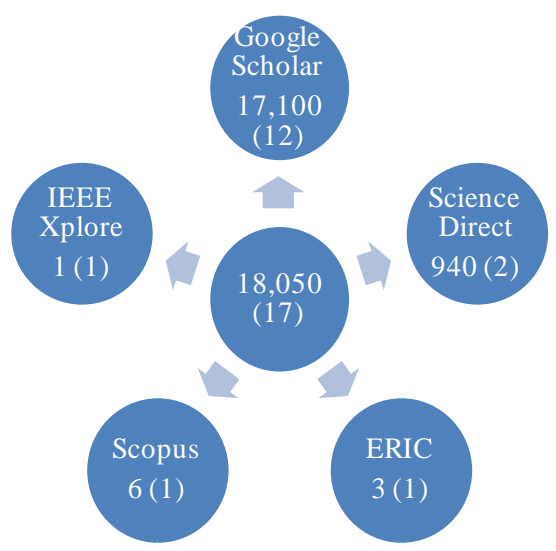

Figure 1. Total number of papers identified in each database and number of papers meeting the inclusion criteria (in brackets). 


\subsection{Vocabulary Learning Strategies}

A number of qualitative studies [23] [24] revealed strategies that second language learners found useful for vocabulary facilitation through gaming situations. Students named, guessing from the context [23]-[25], using of dictionaries [23] [26]-[28], peers' advice [23] [25] [27], language repetitions [25] [27] [29], and interactions with native speakers [30] as the most helpful. Moreover, students in these studies reported the enhanced motivation toward language learning caused by engaging gaming environment. Next sections of the paper examine the effect of learning strategies on vocabulary acquisition through video games in the context of quantitative, mixedmethods, and some qualitative studies.

\subsubsection{Determination Strategies: Contextual Clues}

Although, learning from the context is considered to be complicated for second language learners, context "remains an important source of information" for the vocabulary enhancement [31]. Research on second language learning through video games shows that video games provide opportunity to learn new vocabulary items through contextual clues by associating the written texts or audio directions with actions in the game [32]. Rankin, Gold, and Gooch [33] reported that one intermediate and two Chinese advanced ESL students increased their vocabulary by $40 \%$ through 16 hours of interactions with non-player characters in Ever Quest 2, MMORPG. However, one high-level beginner student experienced cognitive overload. At the same time, all four participants correctly defined $35 \%$ of words that were used only once in conversation with non-player characters and $55 \%$ of words that were introduced more than five times.

In line with Rankin, Gold, and Gooch [33], the analysis of self-report and survey in Chen and Yang's [26] study, which explored the experience of 35 intermediate ESL Taiwanese students playing adventure game Bone, revealed that 11 students mentioned that the game was helpful in terms of vocabulary gains (3.83 \pm 0.80$)$. At the same time, the majority of students reported that both game missions $(n=20)$ and in-game language $(n=11)$ were difficult. Similarly, Yang and Chen [34] reported on research exploring one-hour use of adventure game Back to the Future by 60 Taiwanese ESL freshmen. Students' perceptions derived from Likert scale survey and questioner disclosed that over half of the students found the game itself useful for vocabulary acquisition ( $\mathrm{M}=$ 4.17) and contextual clues $(n=14)$ for better discovery of words' meaning. Few students, however, underlined that in-game vocabulary was challenging.

It is noteworthy, Rankin, McNeal, Shute and Gooch [35] revealed that six advanced ESL Chinese students who had three hours of traditional classroom instructions performed significantly better (ANOVA, $p=0.02$ ) on Vocabulary in Sentence Usage post-test (score 54.78/100) than six advanced ESL Chinese students (score 16.16) who played Ever Quest 2 for four hours. At the same time, statistical significant differences between students were not established for Vocabulary in the Context of the Game and Vocabulary outside the Context of the Game. Nevertheless, authors did not provide any information on what vocabulary strategies were applied in traditional classroom environment. The findings in this section suggest that, although learners find in-game language and missions challenging, contextual clues are beneficial for vocabulary acquisition. However, traditional instructions may be more effective for some aspects of vocabulary recall.

\subsubsection{Determination Strategies: Dictionary, Word Lists, and Vocabulary Exercises}

A number of researchers [36] [37] have raised the question whether the supplemental materials such as dictionary, word lists, and vocabulary exercises facilitate vocabulary acquisition. Miller and Hegelheimer [36] examined the use of simulation game The Sims by 18 intermediate ESL students in the range age from 18 to 35 . The four game sessions of approximately 55 minutes each were integrated into the literacy course curriculum. Students were divided into six groups, which were assigned into each of the three conditions: mandatory supplemental materials, optional supplemental materials, and no materials. Prior gaming, students in mandatory materials group received explicit access to vocabulary instructions including the online Longman dictionary, vocabulary lists with in-game words' definitions and online matching exercises.

The analysis of weekly quizzes revealed that students with mandatory supplemental materials performed better (7.88 \pm 2.48$)$ than students with optional $(6.61 \pm 1.62)$ and no materials $(6.89 \pm 0.58)$. However, the TukeyKramer post-hoc test revealed statistically significant difference only between students' scores who had mandatory and optional materials $(\mathrm{p}=0.035)$. Nevertheless, $94 \%$ of participants reported that supplemental materials were helpful in terms of vocabulary learning. This statement should be treated with caution, as only three stu- 
dents from optional materials group used vocabulary supplemental materials. Overall, students from all groups enhanced vocabulary ( $7.30 \pm 0.73)$, probably by the game itself. More insight into the issue is required, as Miller and Hegelheimer [36] did not provide any clarifications.

In the findings that mirror Miller and Hegelheimer [36], one-way ANOVA analysis of quizzes in Ranalli’s [37] study established statistically significant difference only between students who had mandatory and optional supplemental materials $(\mathrm{MD}=2.78, \mathrm{p}=0.01$ ). Similar to Miller and Hegelheimer [36], students with mandatory materials outperformed $(8.56 \pm 1.33)$ learners with optional $(5.78 \pm 2.22)$ and no materials $(6.89 \pm 1.96)$. Data analysis of post-project survey shed more light on the issue. Although students found the supplemental materials useful for vocabulary learning ( $3.7 \pm 0.5$ ), they reported slightly disagreement that they could play the game without them ( $2.6 \pm 1.3)$. This represents little evidence of vocabulary exercises, word lists, and dictionary effectiveness for vocabulary acquisition through video games.

\subsubsection{Social Strategies: Interactions with Native Speakers}

Interactions in the social settings are seen as one of the key factors in the development of language proficiency. According to sociocultural theorists, "individual emerges from social interaction", which, "includes not only obvious social relationships but also the qualities that comprise higher-order mental activity" [38]. The effectiveness of this strategy is partially supported by both quantitative and qualitative studies. Rankin, McNeal, Shute and Gooch [35] examined 12 advanced ESL Chinese students' four hours interactions with English native speakers in MMORPG Ever Quest 2. Students were randomly assigned into two treatments: gaming with native speakers and gaming alone. The ANOVA analysis of post-test scores revealed statistically significant difference between groups $(\mathrm{p}=0.01)$ : students who played with native speakers performed higher $(55.56 \pm 5.06)$ compared to single players $(82.22 \pm 5.54)$.

In the follow up study, Rankin, Morrison, McKenzie, Gooch and Shute [39] established similar results for 18 Chinese ESL participants who played Ever Quest 2 for four hours. The ANOVA analysis of Vocabulary in a Context of a Gameplay post-test scores revealed statistically significant difference between groups $(\mathrm{p}<0.05)$ : students who played with native speakers performed better (score 83.33/100 ) than students who had traditional classroom instructions (score 60/100) and students who played the game alone (score 57/100). Interestingly, the statistical difference between traditional instruction and single gaming groups were not established. It is noteworthy, students with traditional instructions outperformed (score 54.78/100) students who played alone (score 16.16/100) and with native speakers (score 13.10/100) on Vocabulary outside the Game Context post-test. However, an idea that was unclear was what kind of traditional classroom activities were used. Overall, $82 \%$ of students in both gaming groups enhanced vocabulary.

The positive quantitative findings find support throughPeterson's [30] study that observed the experience of four intermediate level students in MMORPG Wonderland. A sociocultural discourse analysis revealed that social interactions with native speakers were helpful for vocabulary acquisition, especially, slang. Students reported that these interactions were challenging but practically useful. Moreover, students reduced anxiety and established good rapport by means of politeness, humor, informal language, and small talks. A conclusion is that interaction with native speakers positively affects vocabulary acquisition; however, drill-and practice in a traditional classroom environment may be more beneficial for some aspects of vocabulary retention.

\subsubsection{Social Strategies: Interactions with Peers}

Proponents of Language Socialization theory emphasize the importance of scaffolding instructions for language acquisition and argue that social interactions between experienced and less experienced peers in an authentic social environment are beneficial for language acquisition of both [40]. Ranalli [37] reported on research exploring The Sims simulation gameplay of nine intermediate ESL undergraduate students. Analysis of pre- and post-test scores indicated the statistically significant increase (paired-samples t-test: 0.05 ) of vocabulary by $14 \%$. Students reported that gaming experience was enjoyable $(4 \pm 0.5)$ but it was not easy to play the game $(3.4 \pm 1)$. Therefore, they helped each other to understand unknown words and phrases $(4.1 \pm 1)$ and agreed that playing with the partner was enjoyable $(3.9 \pm 1)$ and helpful $(4.2 \pm 1)$. The big idea is interaction with peers along with teacher's supplemental materials result in positive vocabulary outcomes.

\subsubsection{Memory Strategies: Imagery}

According to the cognitive domain of second language acquisition, the learners' ability to connect visual images 
with personal experience facilitates language learning [7]. The findings of Vahdat and Behbahani [41] support this claim. The researchers revealed that 10 Iranian intermediate ESL students who played Runaway: A Road Adventure game for approximately 120 hours outperformed $(16.75 \pm 1.585) 10$ students who had traditional drill-and-practice activities $(14.05 \pm 1.326)$ for the same number of hours. The researchers asserted the features of Runaway, namely, the possibility of connecting the words' definitions with examples and images, searching of those images in game missions, and creation of mental images of words' meaning facilitated vocabulary acquisition. This represents the effectiveness of imagery strategy in the context of video games.

\subsubsection{Cognitive Strategies: Note-Taking}

The cognitive theorists advocate the concept of knowledge automaticity, which represents the transfer of knowledge from a short-term memory into a long-term [42]. The use of appropriate learning strategies facilitates mental behaviours and lead to the complete automaticity of knowledge [7]. Chen and Yang [43] examined the experience of 22 Taiwanese intermediate ESL freshman students playing adventure game Bone. Students were randomly assigned into two experimental conditions. One group was allowed to take notes during playing, while another group was not. Two paired-samples $t$-tests revealed statistically significant difference between vocabulary pre- and post-tests in both groups after two hours of gaming. The post-test scores of note taking group were higher $(6.27 \pm 3.07)$ compared to the pre-test $(4.27 \pm 3.13)$. Similarly, the group without note taking per- formed better on the post-test $(5.91 \pm 1.51)$ compared to the pre-test $(4.09 \pm 1.38)$. An independent samples $t$-test did not find statistically significant difference between groups in vocabulary gains: $\mathrm{t}(20)=-0.99, \mathrm{p}=0.746,95 \%$ $[-0.134,0.97]$. Moreover, researchers reported the gradual reduction of notes that students produced throughout the session. In such a way, the idea is note-taking strategy does not facilitate vocabulary acquisition through adventure video game.

\subsubsection{Cognitive Strategies: Verbal and Written Repetitions}

One of the most-used strategies for vocabulary acquisition is verbal and written receptions. Moreover, 91\% of second language learners find them helpful [9]. Bakar and Nosratirad [27] revealed positive effects of frequent and repeated usage of words in different gaming situations for vocabulary acquisition. Three adult low-level English proficiency learners independently acquired over 120 words through The Sims after two months of playing for approximately 4.5 hours per week. Participants improved their vocabulary scores from pre-test to post-test. Increased mark for participant 1 was 33.33, for participant 2 - 30.00, and for participant 3 - 23.33. Moreover, game environment was motivating for using learned vocabulary outside the game context. In sum, verbal and written repetitions strategies used in game environment facilitate vocabulary learning.

\subsubsection{Metacognitive Strategies: Media}

In the current state of language learning through video games, media interactivity is a controversial issue. On one hand, high interactivity may split attention between the audio-visual game elements and learning [44] so that learners may experience higher cognitive load but still be able to enhance language skills [32]. On the other hand, the cognitive overload [45] caused by interactivity, may limit willingness to communicate [46] [47] of even advanced language proficiency learners [48]. DeHaan, Reed and Kuwada [49] explored the interactive effects of 20 minutes Parappa the Rapper 2 musical video game on noticing and recall of vocabulary of 80 Japanese ESL undergraduate students paired by language and gaming proficiency. Participants were randomly assigned to ether 'gaming' or 'watching' treatments: while one student required completing rap lines by pressing the controller button, another student observed the gameplay. In order to win the game, students should finish the line before the time was off; the more lines missed the more chances to lose the game.

A paired-samples t-test suggested that players recalled significantly fewer words compared to watchers $(\mathrm{t}(39)$ $=11.63, \mathrm{p}<0.05)$. Moreover, after treatment both group of students noticed and recalled less known words than they reported in the written pre-test of game lyrics (e.g., watchers decrease was from 35.8 to 21.70 words, while gamers' from 35.7 words to 7.23 ). Interestingly, two-week delayed vocabulary post-test indicated that watchers forgot more words (from 23.27 to 16.03) than gamers (from 7.42 to 5.15) did. This difference in outcome may be due to the fact that gamers spend more mental effort than watchers, although this difference was not statistically significant $(\mathrm{t}(39)=1.78, \mathrm{p}=0.082)$. Thus, the findings suggest that interactivity of the musical game is less effective for noticing and recall of vocabulary. 


\section{Discussion}

\subsection{Effective Strategies}

The analysis of quantitative, qualitative, and mixed-method studies revealed that ESL learners enhanced vocabulary by means of imagery [41], language repetitions [25] [27] [29] as well as contextual clues given by either non-player characters [24]-[26] [33] [35] or game environment [23]. Similarly, interactions with native speakers [29] [30] [35] [39] and peers' advice [23] [25] [27] [39] positively affected vocabulary outcomes. Additionally, interactions with native speakers in anonymous informal gaming environment reduced anxiety and increased exposure to slang [29] [30] and colloquial language [25]. Nevertheless, researchers expressed concern that "the exposure to informal registers" and "the incorporation of grammatically incorrect forms remains a potential risk for learner participation in MMORPGs (...) where access is provided to native speaker interlocutors" [30] as it may affect the accuracy and complexity in a target language production [47]. To reduce the side effects of interactions with native speakers, learners should get scaffolding instructions.

Although learners increased vocabulary knowledge, they found in-game vocabulary and game missions challenging [24] [26] [34]. Moreover, learners with elementary language proficiency experienced cognitive overload; therefore, it is suggested that video games such as MMORPGs are more beneficial for high-intermediate and advanced learners [33]. In addition, traditional drill-and practice classroom exercises are more effective than gaming in terms of vocabulary items consolidation [35] [39]. At the same time, we question whether commercial video games should be compared to traditional drill-and-practice activities, as they pursue different objective, namely, informal and incidental learning.

\subsection{Less Effective Strategies}

Findings in this section yielded interesting results. A number of qualitative studies revealed that students preferred and frequently used dictionaries to discover the meaning of the words [23] [26]-[28]. Quantitative and mixed method studies provided little evidence of dictionaries as well as word lists, and vocabulary exercises helpfulness [36] [37]. At the same time, combination of supplemental materials with peer's advice was found beneficial for vocabulary enhancement [37]. Due to a high interactivity of video games, note taking [43] and media [49] strategies did not provide enough support for vocabulary learning. A number of researchers revealed that learners experienced confusion with game mechanics as a result they could not focus on language learning [24] [26] [30] [32] [37] [47]. However, this ability enhanced through the mastery in gaming. Thus, scaffolding instructions coupled with practice may help learners to improve both gaming and language skills.

\section{Conclusion}

Learning is happening in video game affinity spaces [50] where people affiliate with "each other primarily in terms of common interests, endeavors, goals, or practices" [51]. This environment encourages learners to share knowledge and enhance skills through goal-oriented interactions. Additionally, game-enhanced learning provides a set of effective strategies, such as language repetitions and contextual clues, to practice and use vocabulary in the authentic context. Some of the strategies such as word lists and dictionary usage are more beneficial when combined with native speakers or peers' interactions. It should be acknowledged that video games are highly interactive and intercultural affinity spaces; therefore, learners need scaffolding support to get accustomed to game mechanics, in-game cultural norms, and colloquial language. The lack of high quality studies and empirical data, however, makes it difficult to draw conclusion of what strategies are more benefit to vocabulary acquisition through video games. Thus, for harder evidence the future research should have a stronger focus on empirical data, not necessarily comparing gaming and traditional instructions [52]. A new taxonomy combining both gaming principles and vocabulary strategies in the context of second language acquisition may shed more light on what in-game learning strategies are more useful.

\section{References}

[1] Hunt, A. and Beglar, D. (2005) A Framework for Developing EFL Reading Vocabulary. Reading in a Foreign Language, 17, 23-59.

[2] Nation, P. and Waring, R. (1997) Vocabulary Size, Text Coverage and Word Lists. In: Schmitt, N. and McCarthy, M., Eds., Vocabulary: Description, Acquisition, and Pedagogy, Cambridge University Press, Cambridge, 6-19. 
[3] Nagy, W.E. and Anderson, R.C. (1984) How Many Words Are There in Printed School English. Reading Research Quarterly, 19, 304-330. http://dx.doi.org/10.2307/747823

[4] Huckin, T. and Coady, J. (1999) Incidental Vocabulary Acquisition in a Second Language. Studies in Second Language Acquisition, 21, 181-193. http://dx.doi.org/10.1017/S0272263199002028

[5] Nation, I.S.P. (1990) Teaching and Learning Vocabulary. Newbury House, New York.

[6] Schmitt, N. (2000) Vocabulary in Language Teaching. Cambridge University Press, Cambridge.

[7] O’Malley, J.M. and Chamot, A.U. (1990) Learning Strategies in Second Language Acquisition. Cambridge University Press, Cambridge. http://dx.doi.org/10.1017/CBO9781139524490

[8] Oxford, R. (1990) Language Learning Strategies: What Every Teacher Should Know. Newbury House, Boston.

[9] Schmitt, N. (1997) Vocabulary Learning Strategies. In: Schmitt, N. and McCarthy, M., Eds., Vocabulary: Description, Acquisition, and Pedagogy, Cambridge University Press, Cambridge, 198-227.

[10] Cook, L.K. and Mayer, R.E. (1983) Reading Strategies Training for Meaningful Learning from Prose. In: Pressley, M. and Levin, J.R., Eds., Cognitive Strategy Research, Springer, New York, 87-131. http://dx.doi.org/10.1007/978-1-4612-5519-2 4

[11] Takač, V.P. (2008) Vocabulary Learning Strategies and Foreign Language Acquisition. Multilingual Matters, Clevedon.

[12] Gee, J.P. (2007) Good Video Games and Good Learning: Collected Essays on Video Games, Learning and Literacy. Peter Lang, New York.

[13] Gee, J.P. (2005) Learning by Design: Good Video Games as Learning Machines. E-Learning and Digital Media, 2, 5-16. http://dx.doi.org/10.2304/elea.2005.2.1.5

[14] Greenfield, P.M., Camaioni, L., Ercolani, P., Weiss, L., Lauber, B.A. and Perucchini, P. (1994) Cognitive Socialization by Computer Games in Two Cultures: Inductive Discovery or Mastery of an Iconic Code. Journal of Applied Developmental Psychology, 15, 59-85. http://dx.doi.org/10.1016/0193-3973(94)90006-X

[15] Keatinge, M.W. (1896) The Great Didactic of John Amos Comenius: With Biographical, Historical, and Critical Introductions. A \& C Black, London.

[16] Thorne, S.L., Black, R.W. and Sykes, J.M. (2009) Second Language Use, Socialization, and Learning in Internet Interest Communities and Online Gaming. The Modern Language Journal, 93, 802-821. http://dx.doi.org/10.1111/j.1540-4781.2009.00974.x

[17] Reinhardt, J. and Sykes, J. (2014) Special Issue Commentary: Digital Game and Play Activity in L2 Teaching and Learning. Language Learning \& Technology, 18, 2-8.

[18] Cornillie, F., Thorne, S.L. and Desmet, P. (2012) Digital Games for Language Learning: Challenges and Opportunities. ReCALL, 24, 243-256. http://dx.doi.org/10.1017/S0958344012000134

[19] Peterson, M. (2013) Computer Games and Language Learning. Palgrave Macmillan, New York. http://dx.doi.org/10.1057/9781137005175

[20] Newman, J. (2004) Videogames. Routledge, London and New York.

[21] Malone, T.W. (1981) Toward a Theory of Intrinsically Motivating Instruction. Cognitive Science, 5, 333-369. http://dx.doi.org/10.1207/s15516709cog0504_2

[22] Prensky, M. (2001) Digital Game-Based Learning. McGraw-Hill, New York.

[23] Turgut, Y. and Irgin, P. (2009) Young Learners' Language Learning Via Computer Games. Procedia-Social and Behavioral Sciences, 1, 760-764. http://dx.doi.org/10.1016/j.sbspro.2009.01.135

[24] Chen, H.J. and Huang, W.C. (2010) Examining the Potentials of Computer Games for English Learning. Proceedings of 2010 3rd IEEE International Conference on Digital Game and Intelligent Toy Enhanced Learning (DIGITEL), Kaohsiung, 12-16 April 2010, 134-138. http://dx.doi.org/10.1109/DIGITEL.2010.35

[25] Ryu, D. (2013) Play to Learn, Learn to Play: Language Learning through Gaming Culture. ReCALL, 25, $286-301$. http://dx.doi.org/10.1017/S0958344013000050

[26] Chen, H.H.J. and Yang, C. (2011) Investigating the Effects of an Adventure Video Game on Foreign Language Learning. Proceedings of the 6th International Conference on E-Learning and Games, Edutainment 2011, Taipei, 7-9 September 2011, 168-175. http://dx.doi.org/10.1007/978-3-642-23456-9_31

[27] Bakar, N.A. and Nosratirad, E. (2013) Sustaining Vocabulary Acquisition through Computer Game: A Case Study. Asian Social Science, 9, 235-242. http://dx.doi.org/10.5539/ass.v9n5p235

[28] Shahriarpour, N. and Kafi, Z. (2014) On the Effect of Playing Digital Games on Iranian Intermediate EFL Learners' Motivation toward Learning English Vocabularies. Procedia-Social and Behavioral Sciences, 98, 1738-1743. http://dx.doi.org/10.1016/j.sbspro.2014.03.601 
[29] Chik, A. (2011) Learner Autonomy Development through Digital Gameplay. Digital Culture \& Education, 3, 30-45.

[30] Peterson, M. (2012) Learner Interaction in a Massively Multiplayer Online Role Playing Game (MMORPG): A Sociocultural Discourse Analysis. ReCALL, 24, 361-380. http://dx.doi.org/10.1017/S0958344012000195

[31] Nagy, W.E. (1995) On the Role of Context in First and Second Language Vocabulary Learning. University of Illinois at Urbana-Champaign, Champaign. http://hdl.handle.net/2142/31277

[32] DeHaan, J.W. (2005) Acquisition of Japanese as a Foreign Language through a Baseball Video Game. Foreign Language Annals, 38, 278-282. http://dx.doi.org/10.1111/j.1944-9720.2005.tb02492.x

[33] Rankin, Y., Gold, R. and Gooch, B. (2006) 3D Role-Playing Games as Language Learning Tools. Proceedings of EuroGraphics 2006, The Eurographics Association, Oxford, 4-8 September 2006, 33-38.

[34] Yang, C.T.Y. and Chen, H.H.J. (2012) Learners' Perceptions of a Commercial Adventure Video Game for Learning English as a Second/Foreign Language. Proceedings of the 20th International Conference on Computers in Education ICCE, Singapore, 26-30 November 2012, 529-536.

[35] Rankin, Y.A., McNeal, M., Shute, M.W. and Gooch, B. (2008) User Centered Game Design: Evaluating Massive Multiplayer Online Role-Playing Games for Second Language Acquisition. Proceedings of the 2008 ACM SIGGRAPH Symposium on Video Games, Los Angeles, 9-10 August 2008, 43-49. http://dx.doi.org/10.1145/1401843.1401851

[36] Miller, M. and Hegelheimer, V. (2006) The SIMs Meet ESL Incorporating Authentic Computer Simulation Games into the Language Classroom. Interactive Technology and Smart Education, 3, 311-328. http://dx.doi.org/10.1108/17415650680000070

[37] Ranalli, J. (2008) Learning English with the Sims: Exploiting Authentic Computer Simulation Games for L2 Learning. Computer Assisted Language Learning, 21, 441-455. http://dx.doi.org/10.1080/09588220802447859

[38] Lantolf, J.P. and Thorne, S.L. (2007) Sociocultural Theory and Second Language Learning. In: VanPatten, B. and Williams, J., Eds., Theories in Second Language Acquisition: An Introduction, Lawrence Erlbaum, Mahwah, 197-221.

[39] Rankin, Y., Morrison, D., McKenzie, M.C., Gooch, B. and Shute, M. (2009) Time Will Tell: In Game Social Interactions that Facilitate Second Language Acquisition. Proceedings of the 4th International Conference on Foundations of Digital Games, Orlando, 26-30 April 2009, ACM, New York, 161-168. http://dx.doi.org/10.1145/1536513.1536546

[40] Duff, P.A. and Talmy, S. (2011) Language Socialization Approaches to Second Language Acquisition. In: Atkinson, D., Ed., Alternative Approaches to Second Language Acquisition, Routledge, New York, 95-116.

[41] Vahdat, S. and Behbahani, A.R. (2013) The Effect of Video Games on Iranian EFL Learners' Vocabulary Learning. Reading, 13, 61-71. http://www.readingmatrix.com

[42] Shiffrin, R.M. and Schneider, W. (1977) Controlled and Automatic Human Information Processing: II. Perceptual Learning, Automatic Attending and a General Theory. Psychological Review, 84, 127-190. http://dx.doi.org/10.1037/0033-295X.84.2.127

[43] Chen, H.J.H. and Yang, T.Y.C. (2013) The Impact of Adventure Video Games on Foreign Language Learning and the Perceptions of Learners. Interactive Learning Environments, 21, 129-141. http://dx.doi.org/10.1080/10494820.2012.705851

[44] Kalyuga, S., Chandler, P. and Sweller, J. (1999) Managing Split-Attention and Redundancy in Multimedia Instruction. Applied Cognitive Psychology, 13, 351-372. http://dx.doi.org/10.1002/(SICI)1099-0720(199908)13:4<351::AID-ACP589>3.0.CO;2-6

[45] Wu, M.L., Richards, K. and Saw, G.K. (2014) Examining a Massive Multiplayer Online Role-Playing Game as a Digital Game-Based Learning Platform. Computers in the Schools, 31, 65-83. http://dx.doi.org/10.1080/07380569.2013.878975

[46] Reinders, H. and Wattana, S. (2011) Learn English or Die: The Effects of Digital Games on Interaction and Willingness to Communicate in a Foreign Language. Digital Culture \& Education, 3, 3-29.

[47] Reinders, H. and Wattana, S. (2015) Affect and Willingness to Communicate in Digital Game-Based Learning. ReCALL, 27, 38-57. http://dx.doi.org/10.1017/S0958344014000226

[48] Rama, P.S., Black, R.W., van Es, E. and Warschauer, M. (2012) Affordances for Second Language Learning in World of Warcraft. ReCALL, 24, 322-338. http://dx.doi.org/10.1017/S0958344012000171

[49] DeHaan, J.W., Reed, W.M. and Kuwada, K. (2010) The Effect of Interactivity with a Music Video Game on Second Language Vocabulary Recall. Language Learning \& Technology, 14, 74-94.

[50] Hayes, E.R. and Duncan, S.C. (2012) Learning in Video Game Affinity Spaces: New Literacies and Digital Epistemologies. Peter Lang, New York.

[51] Gee, J.P. (2004) Situated Language and Learning: A Critique of Traditional Schooling. Routledge, New York.

[52] Reinhardt, J. and Arizona, U. (n.d.) Developing a Research Agenda for Digital Game-Based L2 Learning. University of Arizona, Tucson. http://www.slat.arizona.edu/sites/slat/files/page/gamesresearchagenda.pptx 